\title{
MORPHOLOGICAL VARIABILITY OF SEVERAL INDONESIAN POPULATIONS OF GIANT FRESHWATER PRAWN, Macrobrachium rosenbergii
}

\author{
Imron*), Iskandariah*), Bambang Iswanto"), and Raden Roro Sri Puji Sinarni Dewi*)
}

\begin{abstract}
Patterns in morphological variability have been the main basis for conventional genetic improvement program, particularly in selective breeding. Proper understanding on these patterns hence, is of crucial prerequisite before any scheme of breeding program is undertaken. This study was aimed to explore those morphological variations with emphasis on the assessment of among-population and among-trait variations and assessment of predictive traits that may serve for inter-population differentiation. A total 281 individuals representing four natural populations (Asahan, Ogan, Barito, and Ciasem) and one domesticated stock (GIMacro) were sampled and analyzed for variability in thirteen morphological traits. While descriptive analyses were applied to analyze both among-stock and among-trait variations, discriminant function analysis was used to search for the best traits for interpopulation differentiation. The relative variability, expressed in the coefficient of variation (CV), was used to compare the amount and patterns of morphometric variability both among traits and between stocks. Results showed that total body weight was the most variable trait while the length and meristic traits were of lower level. Discriminant analysis found that rostrum length and abdoment length to be the best morphological discriminators among intraspecific populations. However, the continuous natures of these traits make them have limited applicability for intraspecific population differentiation.
\end{abstract}

KEYWORDS: morphological variability, giant freshwater prawn (GFP), Macrobrachium rosenbergii, coefficient of variation (CV)

\section{INTRODUCTION}

Performance of quantitative characters including weight and length measurements have long been the basis for genetic improvement programs, particularly those using conventional approaches such as selective breeding and crossbreeding. Specifically, genetic improvement is more likely to be conducted in populations showing more variability in quantitative character of commercial interest than those showing less variability. Hence, understanding the nature of these characters including their amount, patterns as well as heritability is of great importance.
Macrobarchium rosenbergii is a freshwater prawn species of commercial interest. It is one of fresh water prawn species capable of attaining the largest maximum size among the member of Macrobrahium genus. It is an indigenous species in the whole of south and south east Asian as well as in northern Oceania and Western Pacific islands, but research activities and commercial purposes has made its distribution expanded through out tropical and subtropical regions of the world (New, 2002). It occurs in various types of coastal freshwater systems including rivers, swamps, lakes, irrigation ditches and canals and ponds.

") Research Institute for Freshwater Fish Breeding and Aquaculture, Sukamandi, Indonesia 
In Indonesia, several natural populations of GFP including Musi (South Sumatera), Kalipucang, Tajung Air (West Java) (Hadie et al., 2004), Makassar (South Sulawesi), Banjarmasin (South Kalimantan), Jambi (central Sumatera), Sukabumi (West Java) (Nugroho et al., 2006), and Barito (Kalimantan) (Hadie et al., 2005) have been identified. Preliminary studies targeting on these populations in the effort to explore for genetic improvement have been conducted.

On the basis of molecular genetic assessment using marker such as 16S RNA mitochondrial gene, Mather \& de Bruyn (2003) and de Bruyn et al. (2004) suggested that global GFP stocks were clustered into two main clades, namely eastern and western forms, divided by Huxley's line. The two clades were hypothetically formed as result of tectonic movement during meiocene era or eustatic changes during pleistocene (Lindenfelser, 1984). Similar patterns of eastern and western forms were also suggested by morphological analyses, particularly in the rostral serration. He characterized the western form as being stouter, having longer rostrum and more number of rostral serration. While reproductive barrier in experimental crossing between populations which part of western form has been reported, no report whether significant variation in morphological traits exist in the respective major form has been published.
This study was aimed to explore the patterns of morphological variability both amongstocks and among-traits and to examine the presence of predictive morphometric characters distinguishing among the existing GFP populations.

\section{MATERIALS AND METHODS}

\section{Sample and Data Collection}

A total of 281 samples representing natural populations including Asahan (North Sumatera), Ogan (South Sumatera) Barito (Kalimantan), Ciasem (west Java) as shown in Figure 1, and a domesticated population (GIMacro) were collected and analyzed. Morphological characters, selected on the basis of inter-individual consistency and easy measurement, including 10 morphometric and 2 meristic traits (Table 1) were determined following description given by Lindenfelser (1984) and Mariappan \& Balasundaram (2004). The traits included were rostrum length (ROSTRUM) and rostrum serration both on the dorsal (DORSER) and the ventral side (VENSER), carapace length and width (CARALENGTH and CARAWIDTH); length and maximum width of the abdomen (ABDLEN and $A B D W I D$ ); length of the first pereiopod and that of its propodus (FSTLEG and PROP); length and maximum width of the telson (TELLEN) and (TELWID); and length of the antennal scale (ANTSCALE). Measurements of length-associ-

\section{INDONESIA}

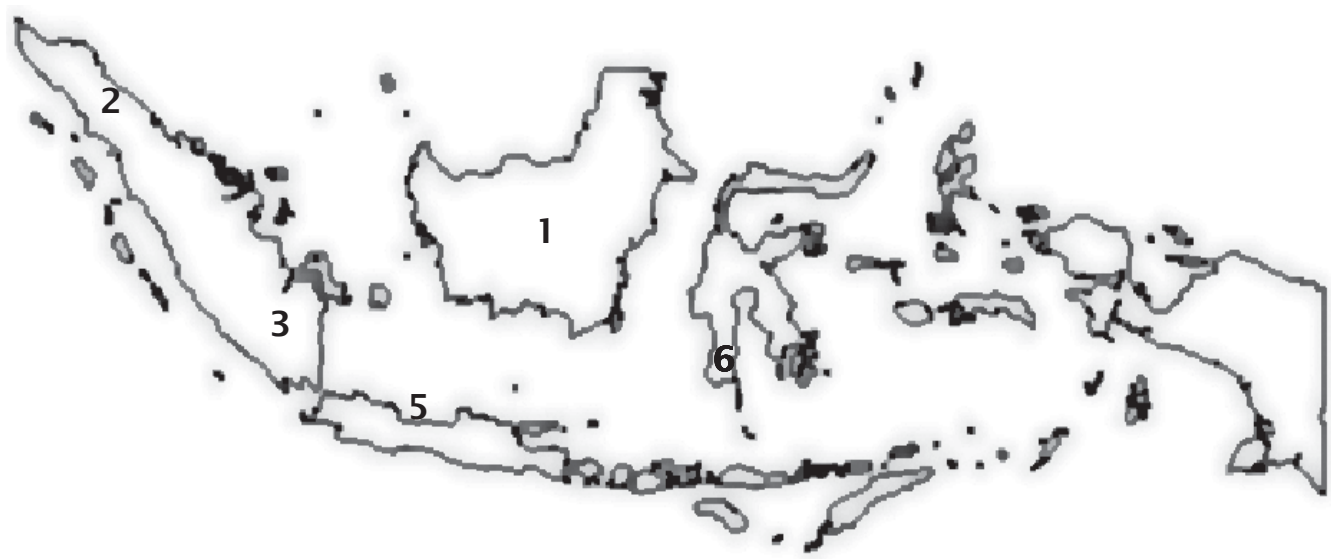

Figure 1. Map of Indonesia showing sampling locations of Indonesian freshwater prawns used in the current study. Number 1, 2, 3, and 5 refer to $M$. rosenbergii populations which are Barito, Asahan, Ogan, and Ciasem, respectively. Number 6 refer to sampling location of M. nipponenese 


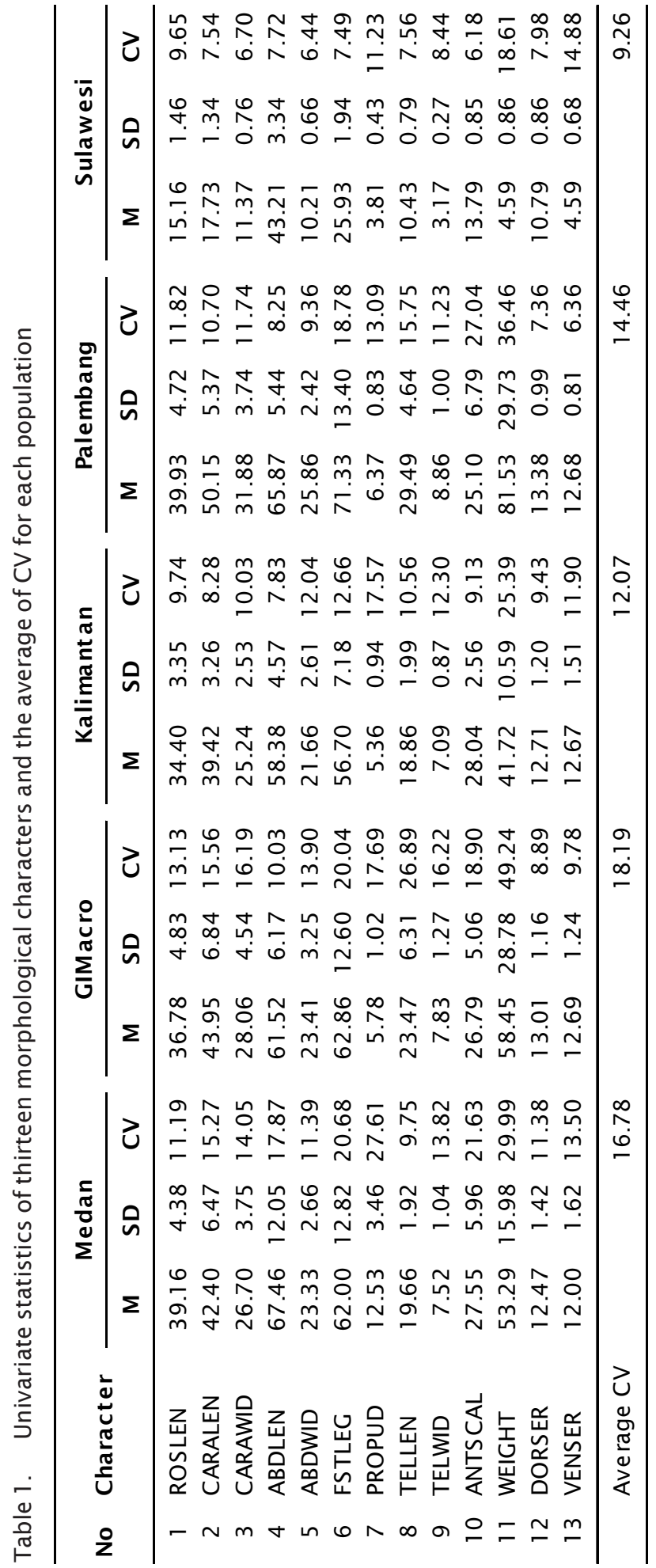


ated traits were taken using a digital caliper to the nearest $0.01 \mathrm{~mm}$ while total body weight was determined using Ohaus analytical balance to the nearest $0.01 \mathrm{mg}$. Meristic characters including DORSER and VENSER were determined manually. Illustration on morphological features upon which measurements conducted was given in Figure 2.

\section{Data Analyses}

\section{Comparisons of morphological variation}

Simple descriptive statistics including means, standard deviation (S) and relative variability, i.e. coefficient of variation (CV), were recorded for each population. The average of CV was computed to allow comparison of univariate variability among populations. The relative variability, which was expressed in terms of coefficient of variation (CV) (Haldane, 1955; Lewontin, 1966; Lande, 1977), was used to display descriptively and to compare quantitatively the amount and patterns of trait variability. The choice of using this kind of variability data, instead of using standard deviation, was meant to eliminate the possible biases which might be appeared due to differences in the mean of the compared populations (Lewontin, 1966). The coefficient of variation of any character was defined as:

$$
C V=(S X 100) / Y
$$

(Sokal \& Rohlf, 1969)

where

S : Standard deviation

$Y$ : Population mean of the trait of interest

Variability profiles of the traits between populations were analyzed using descriptive analysis by displaying the CV values of the traits in both table and graphs and comparing the amount and patterns of these values between the different groups as well as traits.
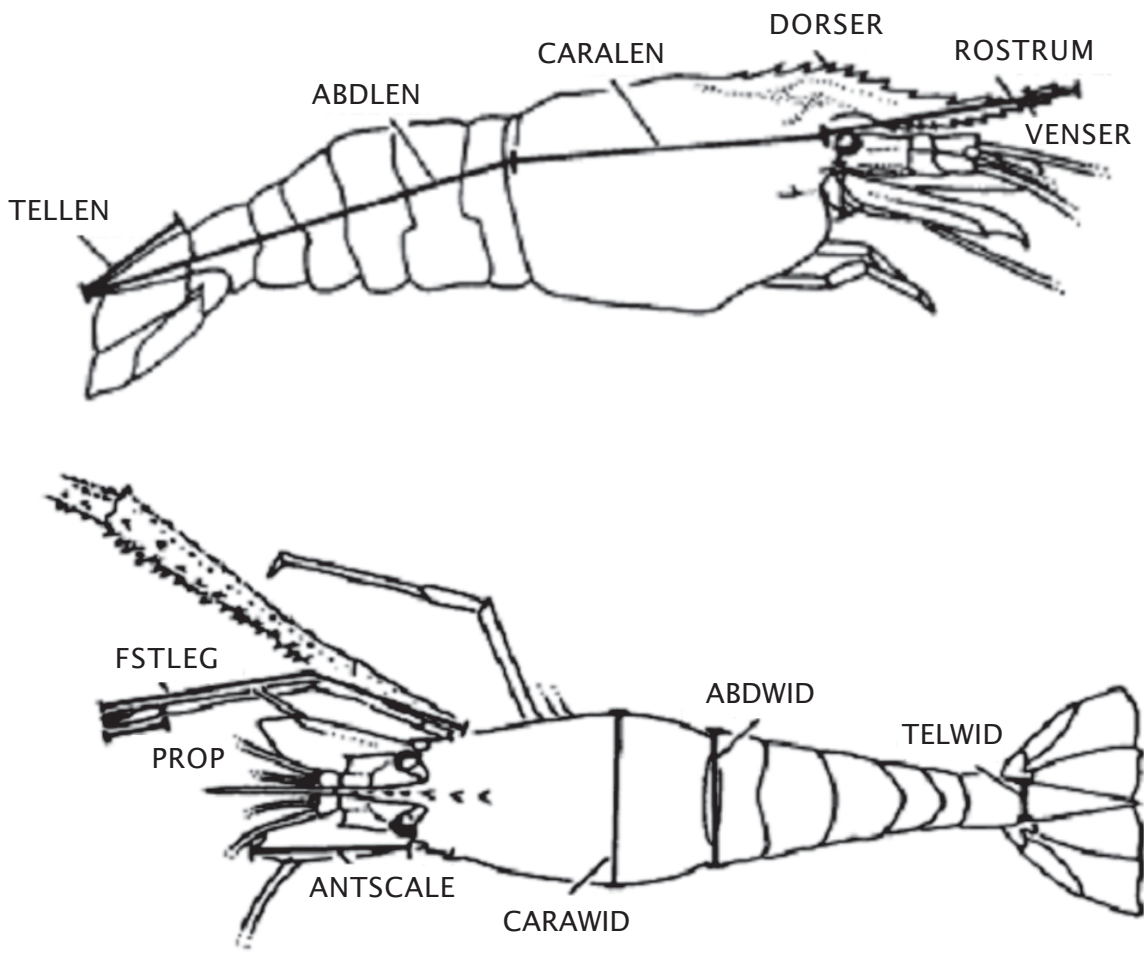

Figure 2. Illustration of morphological traits Macrobrachium rosenbergii, (Lindenfelser, 1984) used for morphological analyses. FSTLEG; first leg, PROP; propudus, ANTSCALE; antennal scale, ABDWID; abdomen width, CARAWID, carapace width, CARALEN; carapace length, TELWID; telson width, TELLEN; telson length, ABDLEN; abdomen length, DORSER; dorsal serration and VENSER; ventral serration 


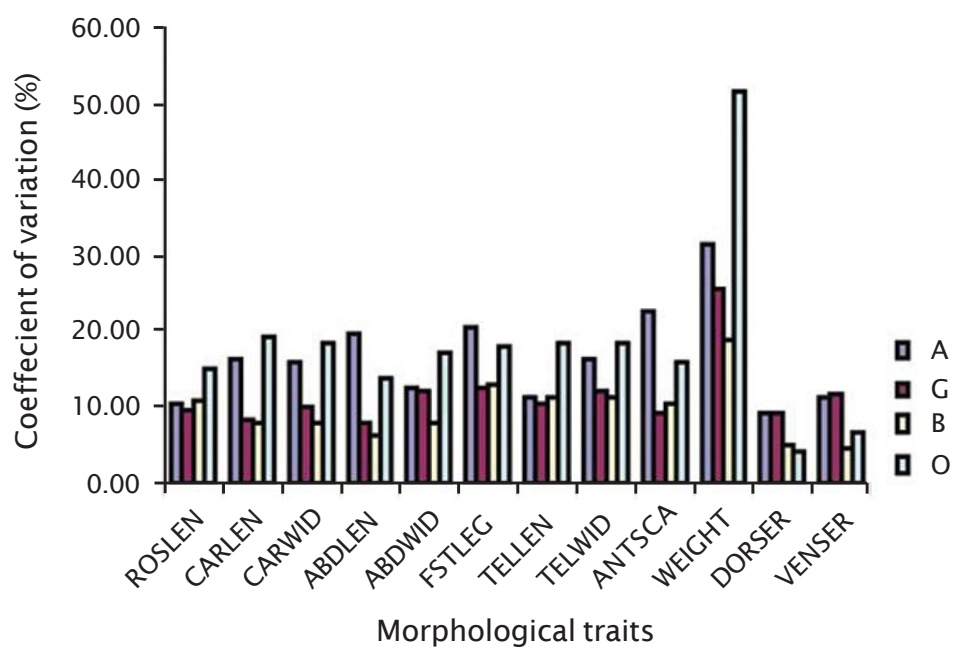

Figure 3. Variability patterns of 12 morphological traits in four populations of Indonesian GFP. A, G, B and O indicate geographic origin of populations or stocks which are Asahan, GIMacro, Barito, and Ogan, respectively. Abbreviations along the abscissa axis refer to morphological traits as completely described in the text

\section{Population identification}

Prior to do morphological analysis of interpopulation differentiation, it is important to recognize whether sexual dimorphisms phenomena exist. Failure to recognize them may confound the results of morphological interpopulation differentiation. To explore possible significant variation in morphological traits between male and female, a multivariate analysis of variance (manova) was applied. For this purpose, only 5 GFP populations were used since the $M$. nipponense sample lacked male individuals. Depending on this preliminary result, subsequent multivariate (discriminant analyses) may treat the data as a single set without considering the sex; i.e. if no sexual dimorphisms in morphological traits of interest are found. Alternatively, analyses have to treat the data of the respective sex separately.

To explore the presence of predictive morphological characters distinguishing among populations, a discriminant function analysis, implemented in Systat version 11, was undertaken. For this purpose, only lengthmeasurement and meristic data were used. The length-measurement data were ratio-transformed (Corruccini, 1977) using carapace length as denominator. This was meant to eliminate possible biases resulting from differences in individual size (Heales et al., 1995). The weight character was excluded from the analysis as it may contain no discriminatory power to distinguish different populations. In addition to five conspecific populations of GFP, one congeneric species of freshwater prawn, Macrobrachium nipponense, was included with the aim to obtain information on the relative similarity of intraspecific relative to the interspecific populations. Relative position of individuals along discriminant functions which reflect their scores were visualized using scatter plots. Ninety five percent centroid and confidence ellipses for each population were also displayed to allow a quick examination on the degree of differentiation among populations.

\section{RESULTS AND DISCUSSION}

\section{Patterns of Morphological Variation}

Average morphological variation among populations (Table 1) shows the highest morphological variation (18.12\%) was found in GIMacro while the least variable was found in Sulawesi populations (9.26). It should be noted however, the Sulawesi population was not representative of Macrobrachioum rosenbergii. Excluding this population from analysis left Barito population as one with the lowest CV average (12.7\%). The other two populations sit in between these two extremes. If the popula- 
tions sampled were obtained from similar environmental conditions, one could speculate on the relative contribution of genetic and environmental condition in producing the observed patterns. However, this is not the case. As previously described, except for GIMacro, which is domesticated population, the rest of the samples were of natural origin that no information was available in relation to age, cohort, relatedness, and breeding population. For these reasons, it is unlikely to address the amount or proportion of relative contribution that resulted from genetic, environment or combination of both.

Among 12 morphometric characters investigated, the highest variation was found in weight character (Figure 3). It ranged from as low as 20\% in Barito to as high as 50\% in Ogan populations. Degree of variation in the remaining character was low and comparable one to another.

\section{Morphological population differentiation}

Depending on the taxa included in the analyses, i.e. whether data consisted of $M$. rosenbergii populations only or combination of $M$. rosenbergii and M. nipponense, either one of two types of morphological differentiation emerged. When analyses involved both taxa, clear population differentiation appeared. Conversely, when analyses restricted to conspecific populations of $M$. rosenbergii, less distinctive population differentiation was observed. Additionally, Preliminary analyses to check the presence of sexual dimorphisms found a positive result. Statistically significant differentiations occurred in most quantitative traits investigated $(\mathrm{P}<0.01)$ using either univariate or multivariate tests (Table 2). Hence, the results of morphological interpopulation differentiation analyses presented here were based upon separate analyses of male and female data.

\section{Intraspecific population differentiation}

Using female data set, plotting individual canonical scores along discriminant function 1 and 2 placed the populations into two main clusters (Figure 4A). The first cluster consists of Barito, Asahan and Ciasem populations characterized by significant overlap, particularly between the first two populations. The second cluster consisted of GIMacro and Ogan populations, which differed from the first three populations in different directions. While the former has high scores in both discriminant function 1 and 2 , the latter has high scores in

Table 2 Summary of univariate and multivariate P-values of F-tests for morphological differentiation between males and females in five populations of giant freshwater prawn. NS indicates non significant while single and double asterisks following the values indicate statistically significant at $\mathrm{P}<0.05$ and $\mathrm{P}<0.01$, respectively

\begin{tabular}{lclrrr}
\hline \multirow{2}{*}{ Trait s } & \multicolumn{5}{c}{ Population } \\
\cline { 2 - 6 } & Barito & Medan & Palembang & GIMacro & Ciasem \\
\hline ROSLEN & $0.000^{* *}$ & $0.206 \mathrm{~ns}$ & $0.000^{* *}$ & $0.000^{* *}$ & $0.000^{* *}$ \\
CARWID & $0.000^{* *}$ & $0.764 \mathrm{~ns}$ & $0.000^{* *}$ & $0.000^{* *}$ & $0.000^{* *}$ \\
ABDLEN & $0.000^{* *}$ & $0.018 *$ & $0.000^{* *}$ & $0.000^{* *}$ & $0.000^{* * *}$ \\
ABDWID & $0.000^{* *}$ & $0.169 \mathrm{~ns}$ & $0.000^{* *}$ & $0.000^{* *}$ & $0.000^{* *}$ \\
FSTLEG & $0.000^{* *}$ & $0.797 \mathrm{~ns}$ & $0.000^{* *}$ & $0.000^{* *}$ & $0.000^{* *}$ \\
TELLEN & $0.000^{* *}$ & $0.151 \mathrm{~ns}$ & $0.000^{* *}$ & $0.000^{* *}$ & $0.000^{* *}$ \\
TELWID & $0.000^{* *}$ & $0.165 \mathrm{~ns}$ & $0.000^{* *}$ & $0.000^{* *}$ & $0.000^{* *}$ \\
ANTSCA & $0.000^{* *}$ & $0.059 \mathrm{~ns}$ & $0.000^{* *}$ & $0.000^{* *}$ & $0.000^{* *}$ \\
DORSER & $0.000^{* *}$ & $0.492 \mathrm{~ns}$ & $0.000^{* *}$ & $0.000^{* *}$ & $0.000^{* *}$ \\
VENSER & $0.000^{* *}$ & $0.587 \mathrm{~ns}$ & $0.000^{* *}$ & $0.000^{* *}$ & $0.000^{* *}$ \\
Multivariate & & & & & \\
statistic & & & & & \\
Wilks' Lambda & $0.000^{* *}$ & $0.116 \mathrm{~ns}$ & $0.000^{* *}$ & $0.000^{* * *}$ & $0.000^{* *}$ \\
\hline
\end{tabular}



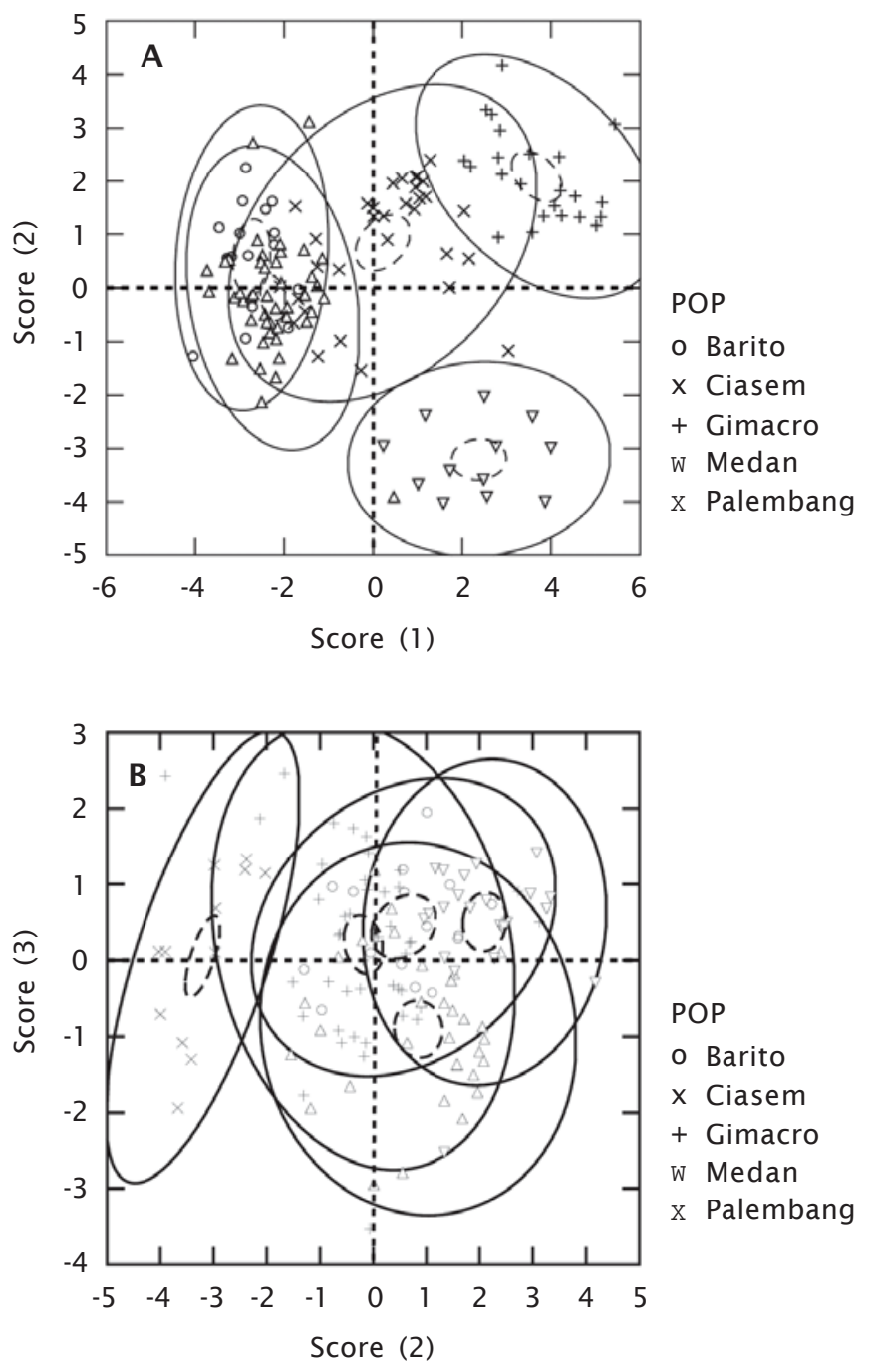

Figure 4. 95\% centroid (inner dashed ellipses) and 95\% confidence interval (outer ellipses) of 5 female Indonesian GFP populations projected along discriminant functions 1 and 2 (A) and 2 and 3 (B)

discriminant function 1 but low scores in discriminant function 2 . Together, discriminant function 1 and 2 which was characterized by the abdomen and rostrum lengths explain $96 \%$ of total variation suggesting that both ROSLEN and ABDLEN are characters with high discriminatory power in differentiating populations of GFP. However, the continuous nature of these characters makes morphological recognition of populations remains complicated. One would not be able to directly recognize whether an individual of GFP belongs to a particular population by solely looking at and measuring the characters. To be able to identify the membership of individual, measurement values have to be put in classification function. This is in contrast to the situation in which characters that have discriminatory power are meristic, as is the case when interspecific comparison was conducted.

The fact that both Ogan and GIMacro were separated from the others and had high scores on discriminant function 1 might reflect, to some degree, evolutionary relationships. This is because GIMacro, which is a domesticated 
stock, was formed using genetic material from Palembang population as one of its base population. Additionally, as discriminant function 1 was strongly characterized by abdomen length (Table 3), high scores of GIMacro and Palembang along that function suggest that, relative to the other populations, both populations had longer abdomen. This is also consistent with the establishment history of the GIMacro which was selectively bred on the basis of growth performance using abdomen length as indicator (Hadie et al. 2004). Plotting individual scores along other functions (discriminant function 3) did not resolve better clustering (Figure 4B).

Different from that previously described, discriminant analyses using male data set did not resulted in a particular pattern. Although centroid of some populations separated one from another, 95\% confidence ellipses show heavy overlap (Figure 5A and 5B). This suggests that males had higher morphological variation than females. It is possible that this is associated with the presence of different morphological features of claw called small males, orange claw and blue claw males. Each type of male has different claw size and structure. These features occurred as result of develop- mental stages and population structure (Ra'anan \& Sagi 1985). The noise appeared in the discriminant results might reflect this situation. Further morphological study with taking this aspect into account may clarify this issue.

\section{Morphological differentiation of interspecific populations}

In contrast to the previously described pattern, discriminant analysis by incorporating $M$ nipponense data to the existed 5 GFP populations resulted in discriminant function with clear-cut differentiation (Figure 6). Plotting of individual canonical scores along discriminant function 1 put two congeneric species into two differentiated groups without any intersection both in the $95 \%$ confidence ellipse and their centroids. Closer looking at the discriminant function 1 , it was found that this function explains $72 \%$ of interspecific variation (Table 4) and was strongly characterized by both body part namely abdomen width and the head portions including carapace width, antennal scale and ventral serration. Despite comparable values, among these characters, the ventral serration apparently contributes

Table 3. List of characters used in discriminant analysis of 5 populations of male and female of Indonesian GFP, and its coefficient canonical discriminant functions (standardized by within variances). Character abbreviations refer to the Figure 2. Characters without coefficient values indicate their exclusion from analysis due to lack of differentiating power

\begin{tabular}{lccccc}
\hline & \multicolumn{3}{c}{ Discriminant Function } \\
\cline { 2 - 3 } \cline { 5 - 6 } & \multicolumn{2}{c}{ Female } & & \multicolumn{2}{c}{ Male } \\
\cline { 2 - 3 } \cline { 5 - 6 } & $\mathbf{1}$ & $\mathbf{2}$ & & $\mathbf{1}$ & $\mathbf{2}$ \\
\hline ROSLEN & 0.372 & 1.139 & & 0.730 & 0.663 \\
CARWID & -0.508 & 0.835 & & & \\
ABDLEN & 1.185 & -0.988 & & 0.685 & -0.243 \\
ABDWID & -0.601 & 0.261 & & -0.133 & 0.019 \\
FSTLEG & - & - & & - & - \\
TELLEN & - & - & & -0.904 & -0.542 \\
TELWID & - & - & & -0.428 & -0.036 \\
ANTSCA & -0.092 & -1.549 & & -0.423 & -1.382 \\
DORSER & - & - & & - & - \\
VENSER & -0.435 & -0.206 & & - & - \\
Eigenvalues & 5.936 & 2.730 & & 4.101 & 1.359 \\
Canonical correlations & 0.925 & 0.856 & & 0.897 & 0.759 \\
Cumulative proportion of & 0.661 & 0.965 & & 0.720 & 0.958 \\
total dispersion (\%) & & & & & \\
\hline
\end{tabular}



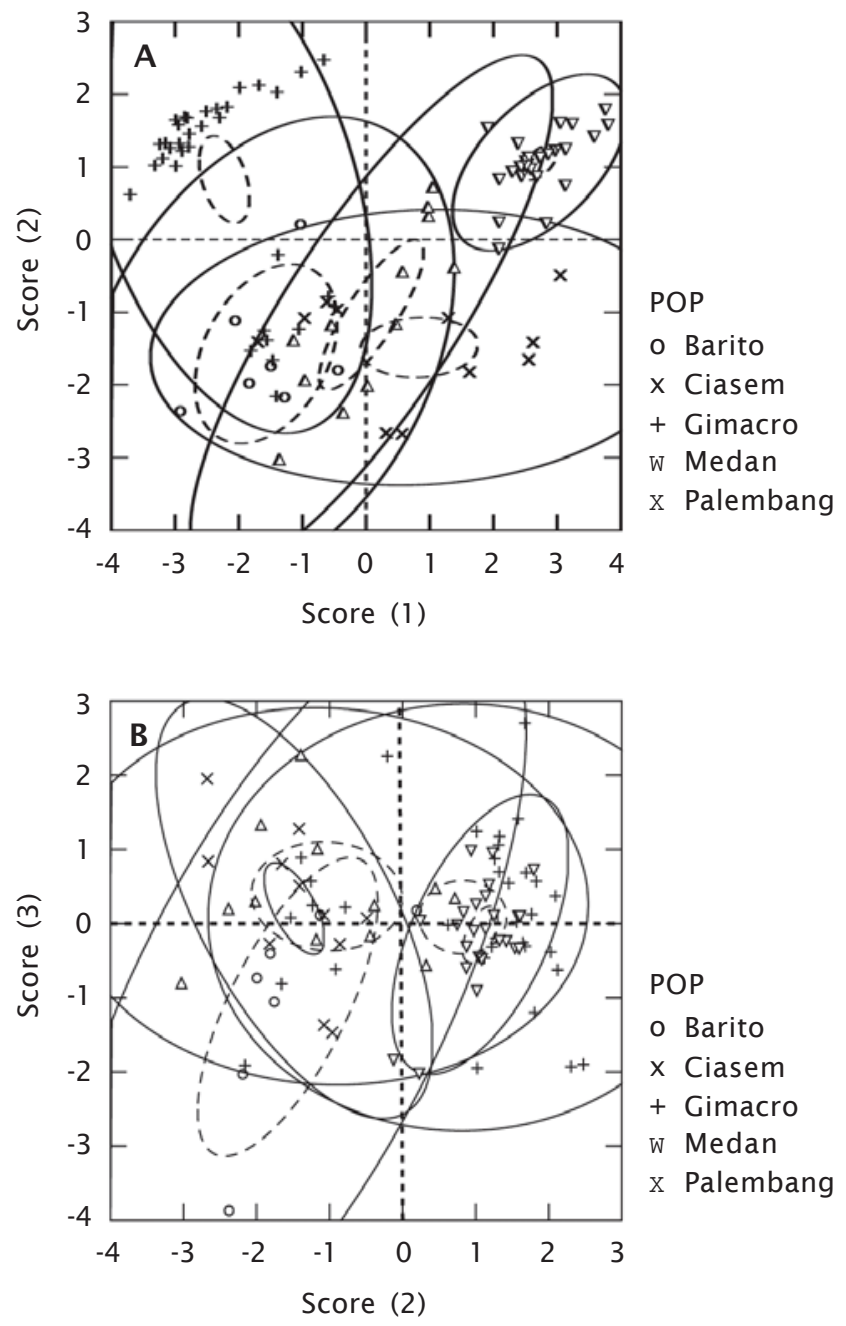

Figure 5. 95\% centroid (inner dashed ellipses) and 95\% confidence interval (outer ellipses) of 5 male Indonesian GFP populations projected along discriminant functions 1 and 2 (A) and 2 and 3 (B)

most to the separation between $M$. rosenbergii and $M$. nipponense populations. While the number of central serration in $M$. rosenbergii ranges from 12 to 13, their number in M niponense was about 5 . It is clear that no overlap was found in the number of ventral serration between these two congeneric species. Plotting individual canonical scores along discriminant functions other than discriminant function 1 did not resolve better pattern of differentiation (Figure 6)

In general, findings emerged from the current study, in which rostrum and its serrations proven to have discriminatory power in distin- guishing both intra and interspecific populations are consistent with previous study (Johnson, 1973). Head portion and abdomen remain the characters showing high variation both for intra and interspecific comparisons. In the case of the former, this study suggests that abdomen and rostrum lengths contributed most in the population differentiation. In the case of the latter, the current study suggests that ventral serration, which is also part of the head play the most important role.

It is well known that phenotypic expression on an organisms is influenced by both genetic and environmental factors. Morphomet- 

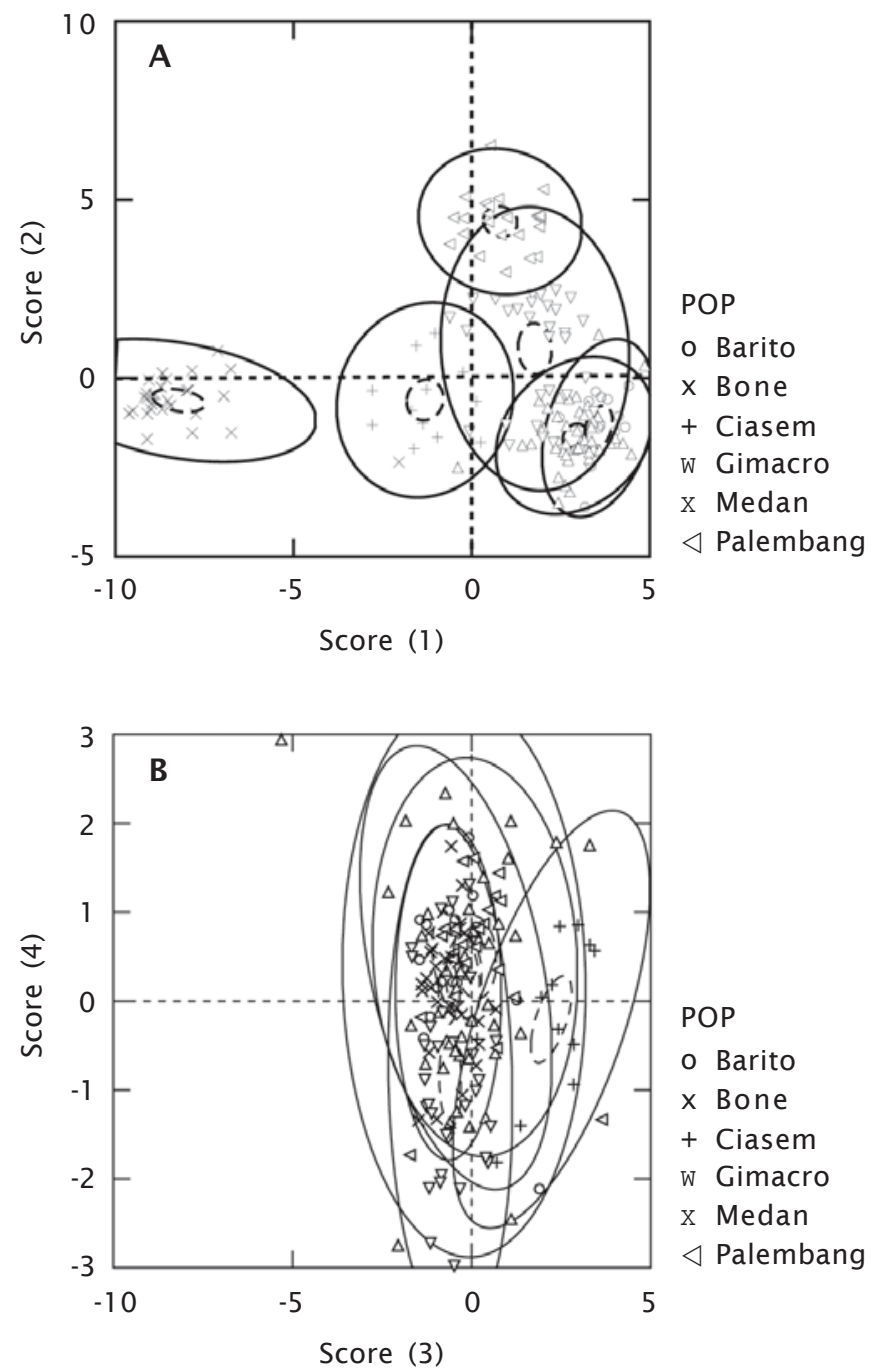

Figure 6. 95\% centroid (inner dashed ellipses) and 95\% confidence interval (outer ellipses) of 6 female Indonesian freshwater prawn populations projected along discriminant functions 1 and 2 (A) and 3 and 4 (B). Single and double asterisks following sampling locations refer to $M$. rosenbergii and $M$. nipponense, respectively

ric characters can show high plasticity in response to differences in environmental conditions, such as food abundance and temperature (Allendorf 1988; Wimberger 1992). Likewise, their expression have also genetic basis. Hence a complementary approach by combining morphological and molecular techniques is needed to address question as to the relative contribution of these factors in determining the expression of morphological characters

\section{CONCLUSIONS}

There was a significant difference in the patterns of morphological variability between length-associated traits and total body weight. The total body weight showed the highest variation among all traits. Conversely, there were only subtle morphological differences among western Indonesian populations of GFP. Furthermore, the continuous nature of morphological characters that were found to reveal 
Table 4. List of characters used in discriminant analysis of 5 female of Indonesian GFP populations and 1 female M. nipponense population, and its coefficient canonical discriminant functions (standardized by within variances). Character abbreviations refer to the Figure 2. Characters without coefficient values indicate their exclusion from analysis due to lack of differentiating power

\begin{tabular}{lccccc}
\hline & \multicolumn{4}{c}{ Discriminant function } \\
\cline { 2 - 3 } \cline { 5 - 6 } \cline { 5 - 6 } & \multicolumn{2}{c}{ Female } & & \multicolumn{2}{c}{ Male } \\
\cline { 2 - 3 } \cline { 5 - 6 } & $\mathbf{1}$ & $\mathbf{2}$ & & $\mathbf{1}$ & $\mathbf{2}$ \\
\hline ROSLEN & 0.474 & 1.069 & & 0.054 & 0.201 \\
CARWID & 0.507 & 0.084 & & -0.483 & 0.467 \\
ABDLEN & -1.252 & 0.046 & & 0.614 & 0.053 \\
ABDWID & 0.555 & -0.149 & & -0.112 & -1.095 \\
FSTLEG & 0.215 & 0.207 & & 0.154 & -0.222 \\
TELLEN & -0.201 & -0.008 & & -0.754 & 0.522 \\
TELWID &. &. & &. &. \\
ANTSCA & -0.592 & -1.108 & & 0.754 & 0.116 \\
DORSER & -0.184 & -0.133 & & -0.406 & 0.212 \\
VENSER & 0.539 & -0.279 & & 0.651 & 0.134 \\
Eigenvalues & 16.4 & 3.949 & & 0.886 & 0.233 \\
Canonic al correlations & 0.971 & 0.893 & & 0.685 & 0.435 \\
Cumulative proportion of & 0.762 & 0.945 & & 0.987 & 0.997 \\
total dispersion (\%) & & & & &
\end{tabular}

discriminatory power restricts its practical use. Consequently, suitable molecular markers should be developed and be applied to genetically identify conspecific populations of GFP.

\section{REFERENCES}

Allendorf, F.W. 1988. Conservation biology of fishes. Conservation Biology. 2:145-148.

Corruccini, R.S. 1977. Correlation Properties of Morphometric Ratios. Systematic Zoology. 26: 211-214.

de Bruyn M, J.A. Wilson, and P.B. Mather. 2004. Huxley's line demarcates extensive genetic divergence between eastern and western forms of the giant freshwater prawn, Macrobrachium rosenbergii. Molecular Phylogenetics and Evolution. 30: 251257.

Hadie L.E., W. Hadie, I.I. Kusmini, H. Supriyadi, Jaelani, and B. Gunadi. 2004. Rekayasa teknologi udang GIMacro dan rekayasa penyempurnaan hasil rekayasa. Paper presented at Temu Nasional udang galah GIMacro di Yogyakarta, 22-23 Juni 2004.
Yogyakarta.

Hadie W, Subandriyo, L.E. Hadie, R.R. Noor. 2005. Analisis kemampuan daya gabung gen pada genotipe udang galah untuk mendukung program seleksi dan hibridisasi. Jurnal Penelitian Perikanan Indonesia. 11:51-56.

Haldane J.B.S. 1955. The Measurement of Variation. Evolution. 9: 484.

Heales D.S., H.G. Polzin, and D.J. Staples. 1995. Identification of of the post larvae of commercially important penaeus species in Australia. In: Rotlisberg P, Hill B, Staples D (eds) Second Australian National Seminar. Seminar Sponsor, Cleveland, Queensland, Australia. p. 41-46.

Johnson D.S. 1973. Notes on some species of the genus Macrobrachium (Crustacea: Decapoda: Caridea: Palaemonidae). J Sing Nat Acad Sci. 3: 273-291.

Lande R. 1977. On Comparing Coefficients of Variation. Systematic Zoology. 26: 214-217. Lewontin R.C. 1966. On the Measurement of Relative Variability. Systematic Zoology. 15: 141-142. 
Lindenfelser M.E. 1984. Morphometric and Allozymic Congruence: Evolution in the Prawn Macrobrachium rosenbergii (Decapoda: Palaemonidae). Systematic Zoology. 33: 195-204.

Mariappan P. and C. Balasundaram. 2004. Studies on the morphometry of Macrobrachium nobilii (Decapoda, Palaemonidae). Brazilian Archives of Biology and Technology. 47: 441-449.

Mather P.B. and de Bruyn M. 2003. Genetic diversity in wild stocks of the giant freshwater prawn (Macrobrachium rosenbergii): Implications for aquaculture and conservation. NACA. 26: 4-7.

New M.B. 2002. Farming freshwater prawns; A manual for the culture of the giant river prawn (Macrobrachium rosenbergii). FAO Fisheries Technical Paper. Vol. 428. FAO, Rome. 212 pp.
Nugroho E, Mulyasari, F. Ali, and Gunawan. 2006. Evaluasi variasi genetik udang galah Makassar-Sulawesi, BanjarmasinKalimantan, Jambi-Sumatera, Sukabumi, Jawa dan GI macro dengan menggunakan penciri mtDNACOI.

Ra'anan Z, and Sagi A. 1985. Alternative mating strategies in male morphotypes of the freshwater prawn macrobrachium rosenbergii (de man). Biol Bull. 169:592-601.

Sokal R.R. and F.J. Rohlf. 1969. Biometry. W.H. Freeman and Company.

Wimberger P.H. 1992. Plasticity of fish body shape - the effects of diet, development, family and age in two species of Geophagus (Pisces: Cichlidae). Biol J. Linn. Soc. 45: 197-218. 